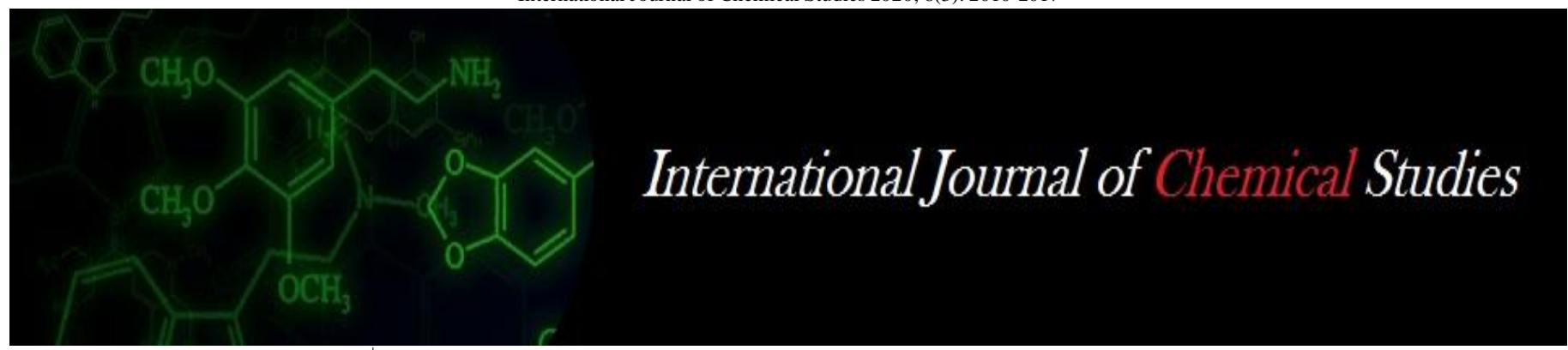

P-ISSN: 2349-8528

E-ISSN: 2321-4902

www.chemijournal.com

IJCS 2020; 8(3): 2010-2017

(C) 2020 IJCS

Received: 20-03-2020

Accepted: 22-04-2020

Md. Delwar Hossen

Department of Chemistry,

Mawlana Bhasani Science and

Technology University, Santosh,

Tangail, Bangladesh

Tanmoy Ojha

Department of Chemistry,

Jahangirnagar University,

Savar, Dhaka, Bangladesh

Pijush Kanti Roy

Department of Chemistry,

Mawlana Bhasani Science and

Technology University, Santosh,

Tangail, Bangladesh

Ashis Kumar Sarker

Department of Chemistry,

Mawlana Bhasani Science and

Technology University, Santosh,

Tangail, Bangladesh

Md. Anamul Haque Shumon

Department of Chemistry,

Mawlana Bhasani Science and

Technology University, Santosh,

Tangail, Bangladesh

DM Shafiqul Islam

Department of Chemistry,

Jahangirnagar University,

Savar, Dhaka, Bangladesh

Corresponding Author:

Md. Delwar Hossen

Department of Chemistry,

Mawlana Bhasani Science and

Technology University, Santosh,

Tangail, Bangladesh

\section{Photocatalytic degradation of sunfix yellow dye in aqueous $\mathrm{ZnO}$ suspension}

\author{
Md. Delwar Hossen, Tanmoy Ojha, Pijush Kanti Roy, Ashis Kumar \\ Sarker, Md. Anamul Haque Shumon and DM Shafiqul Islam
}

DOI: $\underline{\text { https://doi.org/10.22271/chemi.2020.v8.i3ab.9505 }}$

\begin{abstract}
The investigation of photodegradation of sunfix yellow dye in aqueous solution of sunfix yellow/ $\mathrm{ZnO}$ suspension by sunlight was found to be time dependent UV-visible spectrum photodegradation. The absorption peak for sunfix yellow was found at $415.5 \mathrm{~nm}$ in visible region while the absorption of sunfix yellow dye shows disintegrate trend with time and finally disappeared with the increase in irradiation time. The optimum time for the photodegradation of sunfix yellow dye was found to be 150 minutes as well as $96.64 \%$ of sunfix yellow dye was degraded after 150 minutes. The effect of photocatalyst concentration on photodegradation rate of sunfix yellow dye solution was observed by different concentration range of $\mathrm{ZnO}$ from 0.1 to $0.8 \mathrm{~g} / 100 \mathrm{~mL}$, with dye concentration 0.20 to $1.25 \mathrm{mg} / 100 \mathrm{~mL}$ at $\mathrm{pH} 2$ to 11 of sunfix yellow dye solution. The maximum decrease in concentration of sunfix yellow dye solution was found for the $0.25 \mathrm{mg} / 100 \mathrm{~mL}$ during 150 minute of radiation. The optimum catalyst concentration was found to be $0.2 \mathrm{~g} / 100 \mathrm{~mL}$. $\mathrm{pH}$ of the suspension turned out to be an efficient factor for the photodegradation of sunfix yellow dye and the optimum $\mathrm{pH}$ was noticed to be 10 .
\end{abstract}

Keywords: Sunfix yellow, photodegradation, photocatalyst, zinc oxide and suspension

\section{Introduction}

In recent years the most momentous and eye-catching issue is environment pollution and ongoing increase in contamination due to the colossal development of extending industrialization ${ }^{[1]}$. In addition to other pollutants colored wastewater material known as dye is also one of the most dangerous and exceedingly hazardous pollutants released from various industries and causes serious environmental problem ${ }^{[2]}$. It has been estimated that in every year over $7 \times 10^{5}$ tons of dyestuff is produced from 10,000 commercially available dyes all over the world as well as $10-15 \%$ of the dyes used are lost with the dye processing which are discharged with the industry effluent [3]. Many of these dyes are non-biodegradable and carcinogenic too thus menace both ecosystem and aquatic lives leading to an enormous environmental damage ${ }^{[4]}$. Industry owners in third world countries (e.g. Bangladesh) are seem to be very reluctant to run effluent treatment plant (ETP) due to the high cost of chemicals required to biodegrade these dyes and poor monitoring authority. As a result, prior to discharge the wastewater there is no treatment involved in most of the cases and thus these dyes easily entered ecological system and change the environment pattern causing distractive nature around living things ${ }^{[5]}$. Therefore, finding an eco-friendly and cost effective way to decolorizing these dyes is now very much crucial and essential for us all. A huge number of different methods of physical, chemical and biological methods like adsorption, membrane process, coagulation had been applied to decolorized waste water dyes but these methods conclude some limitation too ${ }^{[6-7]}$. So as a part of continuous advancement about digging out an adorable way now a day's photodegradation of dyes using different photocatalyst has become the most promising method being a potential solution to all those previous limitation ${ }^{[8]}$. Photocatalysts exerts some special advantages as they being non-toxic, stable and having excellent oxidative power ${ }^{[9]}$. With the rising use of photocatalyst a huge number of photocatalyst like $\mathrm{ZnO}, \mathrm{TiO}_{2}, \mathrm{CdS}$ etc. have been applied to clean up primary pollutant ${ }^{[10]}$. Nasr et al. (1996) utilized visible light induced degradation of the textile di azo dye Naphthol Blue Black (NBB) using $\mathrm{TiO}_{2}$ semiconductor nanoparticles with the help of diffuse reflectance transient absorption and FTIR techniques and elucidate the mechanistic details of the dye 
degradation obtaining a colorless naphthaquinone like end product ${ }^{[11]}$. $\mathrm{Xu}$ and Langford (2001) examined photodegradation of a textile dye $X_{3} B$ using either UV $(\lambda \geq 320$ $\mathrm{nm})$ or Visible light $(\lambda \geq 450 \mathrm{~nm})$ over three catalysts of highly adsorptive $\mathrm{TiO}_{2}$ nanoparticles in water and interestingly found that the relative activity among the catalysts was similar to that demonstrated in the photocatalytic reaction ${ }^{[12]}$.

Stylidi et al. (2003) studied the use of a solar light simulating source (450W Xearc lamp) to degrade aqueous solutions of acid orange 7 in $\mathrm{TiO}_{2}(\mathrm{P} 25)$ suspensions and found that the dye adsorbs on $\mathrm{TiO}_{2}$ and undergoes a series of oxidation steps, which lead to decolorization and formation of a number of intermediates, mainly aromatic and aliphatic acids ${ }^{[13]}$. Sangchakr et al. (1995) studied photocatalytic degradation of sodium benzene sulfonate and its substituted compounds using $500 \mathrm{~W}$ super high pressure mercury lamp in $\mathrm{TiO}_{2}$ suspension which lead to identification of one major and two minor intermediate products; $p$-phenolsulfonic acid, hydroquinone and $p$-quinone ${ }^{[14]}$. Tanaka et al. (2000) studied photodegradation of seven azo dyes in $\mathrm{TiO}_{2}$ suspension under illumination by a $500 \mathrm{~W}$ super high-pressure mercury lamp and ended up with an indication that in the photocatalytic degradation of azo dyes proceeded through both oxidation and reduction ${ }^{[15]}$. Neppolian et al. (2002) utilized solar light to treat hazardous and toxic of textile wastewater using $\mathrm{TiO}_{2}$ photocatalyst containing $4 \times 10^{-4} \mathrm{M}$ dye was completely degraded in $24 \mathrm{~h}$ irradiation time and the interference of auxiliary chemicals such as sodium carbonate and sodium chloride on photocatalytic degradation was found to be substantially affected the photodegradation efficiency [16]. Silva and Faria (2003) investigated the photochemical and photocatalytic degradation of aqueous solutions of an azo dye, Solophynyl Green (SG) BLE 155\%, by UV irradiation which is effective for low initial concentrations of dye as well as photocatalytic degradation was carried on $\mathrm{TiO}_{2}$ mixed with different activated carbons (AC) for higher concentration of dyes observing that the presence of the activated carbon enhanced the photo efficiency of the $\mathrm{TiO}_{2}$ photocatalyst ${ }^{[17]}$. Guillard et al. (2003) degraded anionic (Alizarin S (AS), azoMethyl Red (MR), Congo Red (CR), Orange G (OG)) and cationic (Methylene Blue (MB)) dyes either individually or in mixtures using UV irradiated $\mathrm{TiO}_{2}$ in suspension or supported on glass and rod and found high photocatalytic activities for $\mathrm{TiO}_{2}$ coated on glass by the sol-gel method ${ }^{[18]}$. Conventional techniques used for dye degradation are non-destructive in nature as they only convert the non-biodegradable pollutants into different type of sludge, giving rise to a new category of contamination, which requires additional treatment but during photocatalytic degradation of dyes, photocatalysts can completely degrade most of the non-biodegradable dyes along with other biodegradable dyes ${ }^{[19-21]}$. Sunfix yellow dye (reactive yellow) is also a dye that release from textile industry and contribute to the environmental problems. Therefore, sunfix yellow dye must be removed from the wastewater before discharging.

In this paper, we have maintained the limelight of our study on focusing the photocatalytic degradation of sunfix yellow dye in presence of $\mathrm{ZnO}$ photocatalyst and the effect of various parameters like $\mathrm{pH}$ of the medium, concentration of the sunfix yellow dye solution and the amount of $\mathrm{ZnO}$ photocatalyst on the photodegradation of sunfix yellow dye.

\section{Materials and methods}

\section{Chemicals and instrumentation}

Sunfix yellow dye, zinc oxide $(\mathrm{ZnO})$, sodium hydroxide $(\mathrm{NaOH})$ and hydrochloric acid $(\mathrm{HCl})$ were merchandise from chemical market in Bangladesh and were used in this study as received i.e. without any additional purification. The major apparatus used during the course of this study were electrical balance, oven, UV-visible spectrophotometer, $\mathrm{pH}$ meter and laboratory centrifuge machine. In addition, of these apparatus some exceeding glass and plastic apparatus like graduate pipette, volumetric flasks, bulk pipette, reagent bottles, funnel, and beaker were also used for measurements and data collection.

\section{Preparation of stock solution of sunfix yellow dye and zinc oxide ( $\mathrm{ZnO})$ suspension}

All the aqueous solutions were prepared with deionized water. The $\mathrm{ZnO}$ suspension was prepared by taking $2.0 \mathrm{~g}$ of $\mathrm{ZnO}$ in a $100 \mathrm{~mL}$ beaker and $5 \mathrm{~mL}$ of deionized water was added to it. The suspension was covered with white paper and kept overnight due to ensure the accurate reaction between $\mathrm{ZnO}$ and deionized water. Further dilutions were carried out by varying the amount of $\mathrm{ZnO}$ in same amount of deionized water when it was necessary. Stock solution of sunfix yellow dye was prepared by dissolving $1.00 \mathrm{~g}$ of sunfix yellow dye in $1000 \mathrm{~mL}$ of deionized water in flask, which made the concentration of the solution having molarity, $1 \times 10^{-3} \mathrm{M}$. In case of the necessity of dilute solution, this stock solution was diluted by varying the amount of deionized water up to expected amount. The concentration ranges $0.2 \mathrm{mg} / \mathrm{mL}$ to $1.25 \mathrm{mg} / \mathrm{mL}$ were used for the measurements.

\section{Concentration measurement and calibration of sunfix yellow dye}

To calculate the concentration of the sample from each experiment, various concentrations of the natural dye solutions were prepared and the absorbance were measured using a UV-visible spectrophotometer over a range from 200 to $1100 \mathrm{~nm}$, which leads to a calibration curve for the dye solution. The calibration curve for sunfix yellow dye solution over a range of concentration demonstrating that the absorbance of the sample increases with the increase in concentration. Concentration of the sample was then determined by using the Beer-Lambert equation as follows:

Absorbance $=\varepsilon C_{\mathrm{s}} 1$

Where, $\varepsilon=$ Molar absorptivity or constant,

$\mathrm{C}_{\mathrm{s}}=$ Concentration of sample, and

$1=$ Thickness of absorbing medium $(1 \mathrm{~cm})$.

Therefore, Dye concentration $(\mu \mathrm{mol} / \mathrm{L})=$ absorbance $/ \varepsilon$

\section{Photocatalytic degradation of sunfix yellow dye}

The photodegradation of sunfix yellow dye was carried out in the presence of sunlight. About $0.2 \mathrm{~g}$ of $\mathrm{ZnO}$ was mixed with $100 \mathrm{~mL}$ dye solution and the resultant solution was kept in the sunlight for photodegradation of the dye. The degradation time was monitored by using a stopwatch meanwhile a certain portion of the irradiated solution was taken in a small beaker after a definite time interval and the absorbance of the solution was measured by using UV-visible spectrophotometer.

\section{Determination of initial rate of degradation}

The initial rate of degradation is very much important for mechanistic investigation of a photodegradation reaction. The pseudo first order rate constant $\left(\mathrm{k}^{\prime} \mathrm{min}^{-1}\right)$ was obtained from the slope of $\ln \mathrm{A}$ vs. time plot according to following equation and the concentration of the dye solution [Dye] was measured at different time.

$\mathrm{R}_{\mathrm{i}}=-\mathrm{d}[$ Dye $] / \mathrm{dt}=\mathrm{k}^{\prime}[\text { Dye }]_{0}$

$\mathrm{R}_{\mathrm{i}}=\mathrm{k}^{\prime} \mathrm{A}_{0} / \sum \mathrm{l}(\mathrm{A}=\Sigma[\mathrm{Dye}] \mathrm{l})$ 
Here,

$\mathrm{R}_{\mathrm{i}}=$ Initial rate $\left(\mathrm{M}^{-1} \mathrm{~min}^{-1}\right)$,

$\mathrm{A}_{0}=$ Absorbance at $\mathrm{t}=0$,

$\sum=$ Molar absorbance coefficient $\left(\mathrm{M}^{-1} \mathrm{~cm}^{-1}\right)$, and

$1=$ Cell path length $(1 \mathrm{~cm})$.

The initial rate of degradation also can be measured from the slope of the tangent drawn at the initial absorbance of dye vs. time profile by assuming that all the fallen light is completely absorbed by the system.

\section{Determination of the percent $(\%)$ of degradation}

The percent $(\%)$ of degradation of sunfix yellow dye was determined by using the Beer-Lambert law for dilution solution as follows:

$\mathrm{A}=\boldsymbol{\varepsilon}[$ Dye $] 1$

Since, $\Sigma$ and 1 are constant, then
A $\infty[$ Dye $]$

$\mathrm{A} \infty[\mathrm{Dy}]_{0}$

$\mathrm{A} \infty[\text { Dye }]_{\mathrm{t}}$

Therefore, $(\%)$ of degradation $=\frac{A_{0}-A_{t}}{A_{0}} \times 100$

Where, $[\text { Dye }]_{0}=$ Concentration of dye at time $\mathrm{t}=0$,

[Dye] $=$ Concentration of dye at time $t$,

$\mathrm{A}_{0}=$ Absorbance of dye at time $\mathrm{t}=0$, and

$A_{t}=$ Absorbance of dye at time $t$.

\section{Results and discussion}

Absorption spectra of the sunfix yellow dye solutions

The absorption spectrum of sunfix yellow dye in aqueous solution was measured by a UV Spectrophotometer at $30^{\circ} \mathrm{C}$. The spectrum are given in Fig 1. The maximum wavelength $\left(\lambda_{\max }\right)$ of sunfix yellow was found to be $415.5 \mathrm{~nm}$ for $\mathrm{pH} 2-13$.

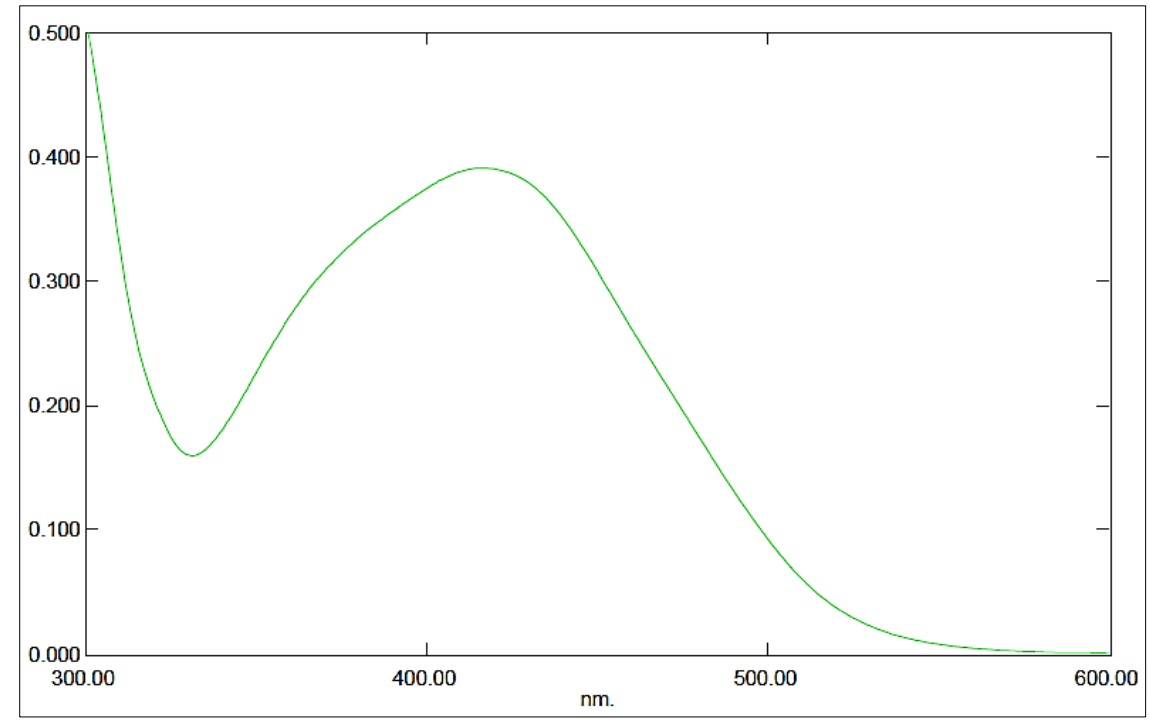

Fig 1: UV spectrum of sunfix yellow dye in solution ( $\mathrm{pH} 2-13)$.

\section{Effect of pH on photodegradation of sunfix yellow dye by}

\section{$\mathrm{ZnO}$}

$\mathrm{pH}$ of the solution is a vital parameter that exerts a huge effect on the photocatalytic degradation of a particular dye. Hence, the investigation of the photodegradation of the sunfix yellow dye in presence of $0.2 \mathrm{~g} \mathrm{ZnO}$ as a photocatalyst was carried out at different $\mathrm{pH}$ range between 2 and 11 at a resolute dye concentration of $0.25 \mathrm{mg} / \mathrm{mL}$. In case of altering the $\mathrm{pH}$ condition into acidic and alkaline medium, $\mathrm{HCl}$ and $\mathrm{NaOH}$ solution were added respectively.

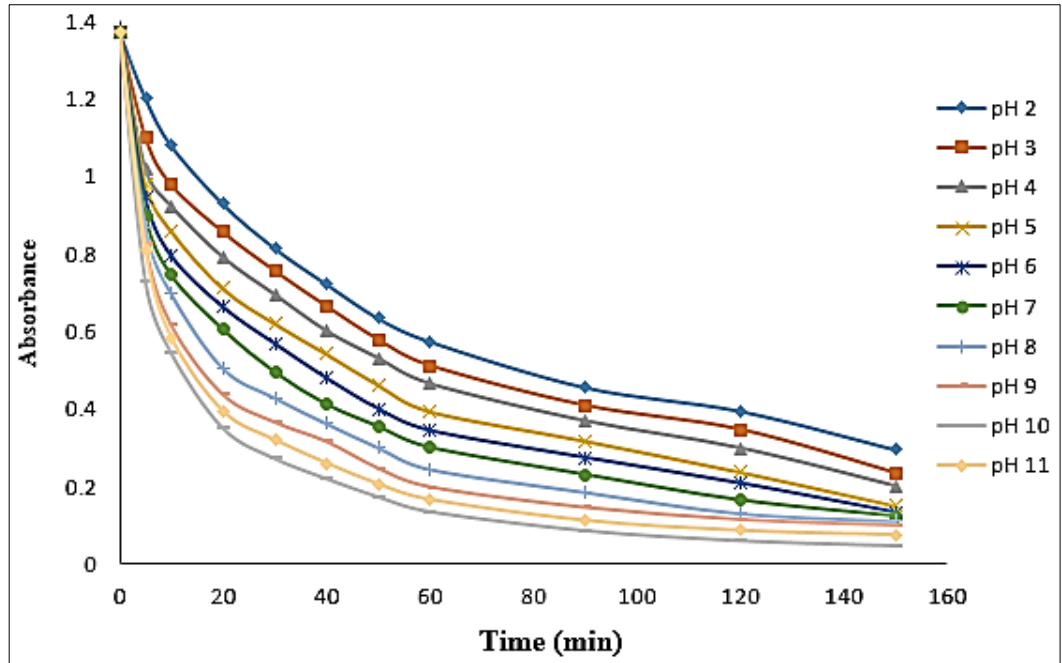

Fig 2: Changes in absorbance with time (min) for photodegradation of sunfix yellow dye at different $\mathrm{pH}$ solution. 


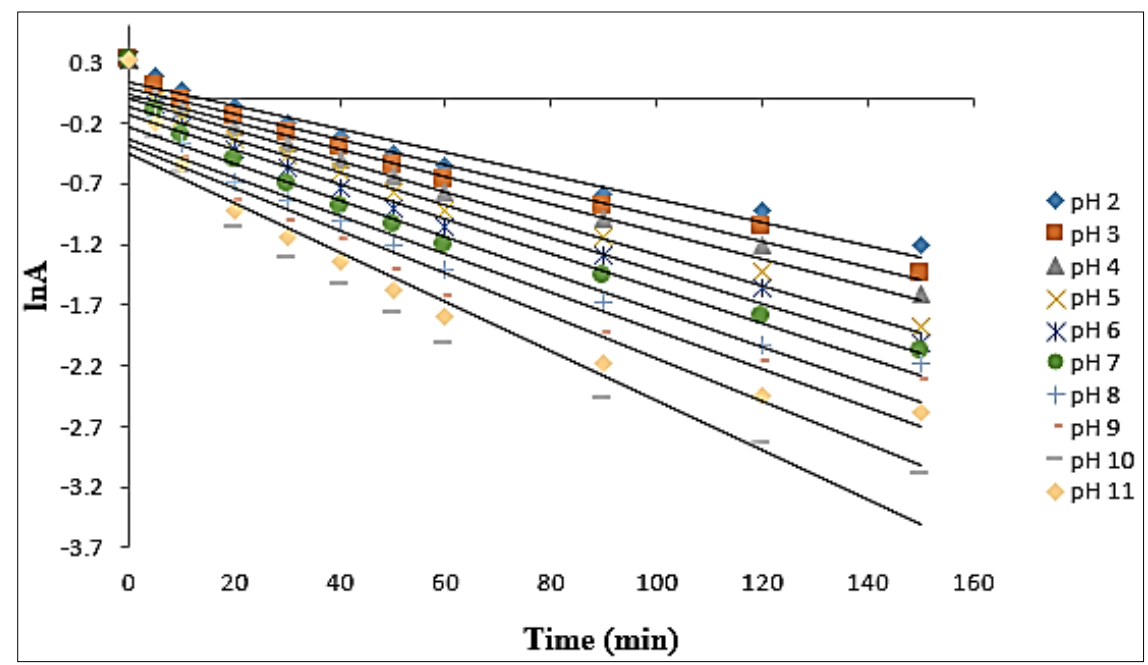

Fig 3: Changes in lnA with time (min) for photodegradation of sunfix yellow dye at different $\mathrm{pH}$ solution.

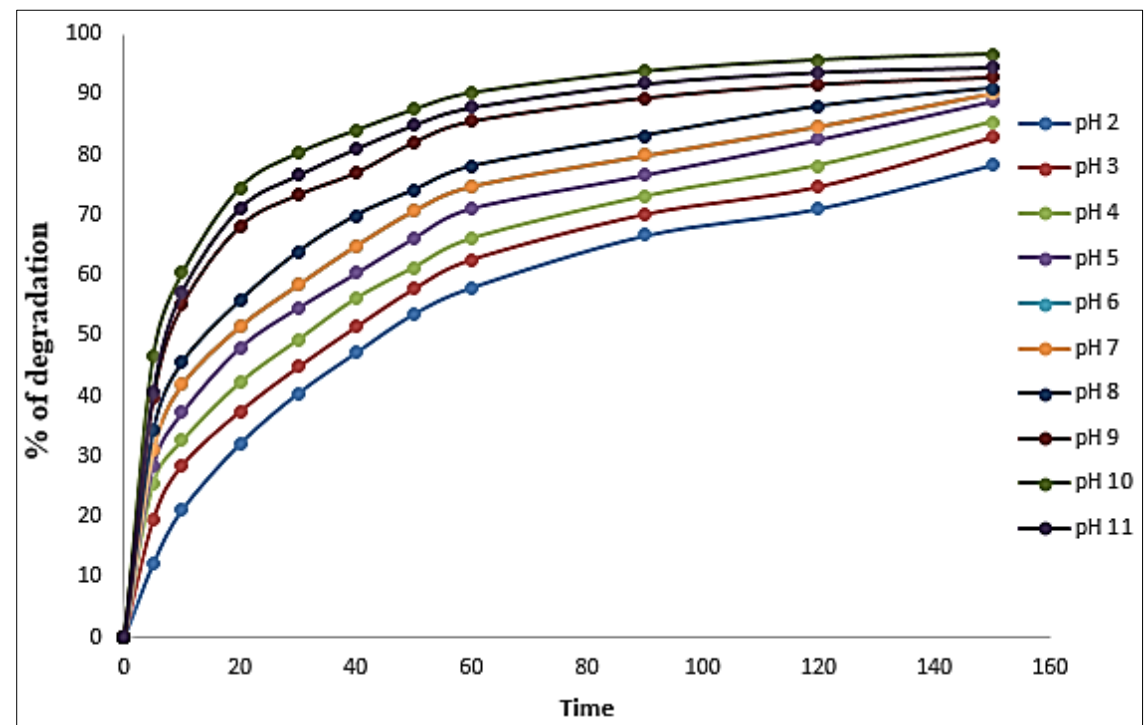

Fig 4: Changes in percent $(\%)$ of degradation with time (min) for photodegradation of sunfix yellow dye at different pH solution.

From (Table 1), it is evident that progressive values of $\mathrm{pH}$ leads to the cumulative increase in photodegradation of sunfix yellow dye upto 10 and a decline in the percent of photodegradation arising at a $\mathrm{pH}$ more than 10 . The enhancement in photodegradtion upto a $\mathrm{pH}$ value 10 can be clarify on the basis of the adsorption of sunfix yellow species on the $\mathrm{ZnO}$ photocatalyst and this improvement in photodegradation is due to the easy adsorption of the sunfix yellow dye on positively charged $\mathrm{ZnO}$ suspension.

The diminish nature in photodegration at higher $\mathrm{pH}(>10)$ can also be elucidate with the rate of adsorption of dye species on the photocatalyst suspension. In higher alkali medium, the degradation was not satisfactory because adsorption of anionic dye on similar type negatively charged photocatalyst. Therefore, the adsorptions of dye species get more resistance while adsorbing on photocatalyst suspension, which guided to a downfall in photodegradation of sunfix yellow dye. Hence, suitable alkaline condition (not more than 10) could be used for photodegradation of sunfix yellow dye. However, the maximum photodegradation of sunfix yellow dye appeared at $\mathrm{pH} 10$ was $96.64 \%$ which signify that a slightly higher $\mathrm{pH}$ is appreciable for the photodegradation of sunfix yellow dye.

Table 1: Percent of photodegradation for the sunfix yellow dye over the different $\mathrm{pH}$ range.

\begin{tabular}{|c|c|}
\hline $\mathbf{p H}$ & Percent (\%) of degradation \\
\hline 2 & 78.32 \\
\hline 3 & 82.84 \\
\hline 4 & 85.32 \\
\hline 5 & 87.90 \\
\hline 6 & 89.21 \\
\hline 7 & 90.22 \\
\hline 8 & 90.94 \\
\hline 9 & 92.77 \\
\hline 10 & 96.64 \\
\hline 11 & 94.42 \\
\hline
\end{tabular}


Effect of initial dye concentration on photodegradation of sunfix yellow dye by $\mathrm{ZnO}$

Initial dye concentration plays a significant role in the photocatalytic degradation of any dyes as the degradation of the dye also depends on the convenient availability of the dye species on the photocatalyst suspension. The impact of initial dye concentration on the photodegradation of sunfix yellow dye was investigated by varying the initial concentration of the sunfix yellow dye from $0.20 \mathrm{mg} / \mathrm{mL}$ to $1.25 \mathrm{mg} / \mathrm{mL}$ at constant amount of $\mathrm{ZnO}(0.2 \mathrm{~g})$ and constant $\mathrm{pH}(10)$ of the suspension.

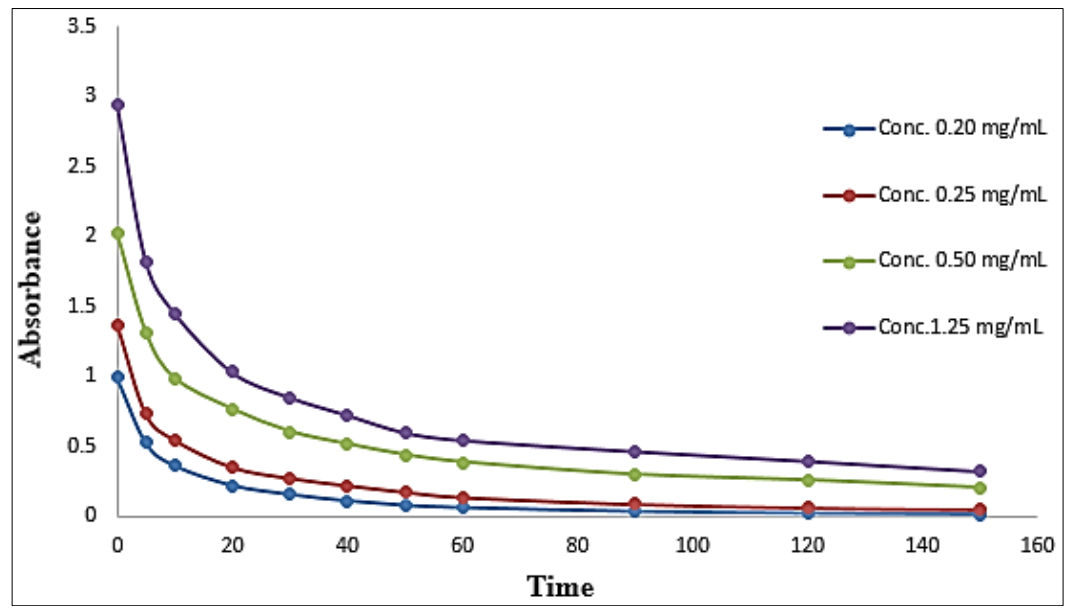

Fig 5: Changes in absorbance with time (min) for photodegradation of sunfix yellow dye at different initial dye concentration.

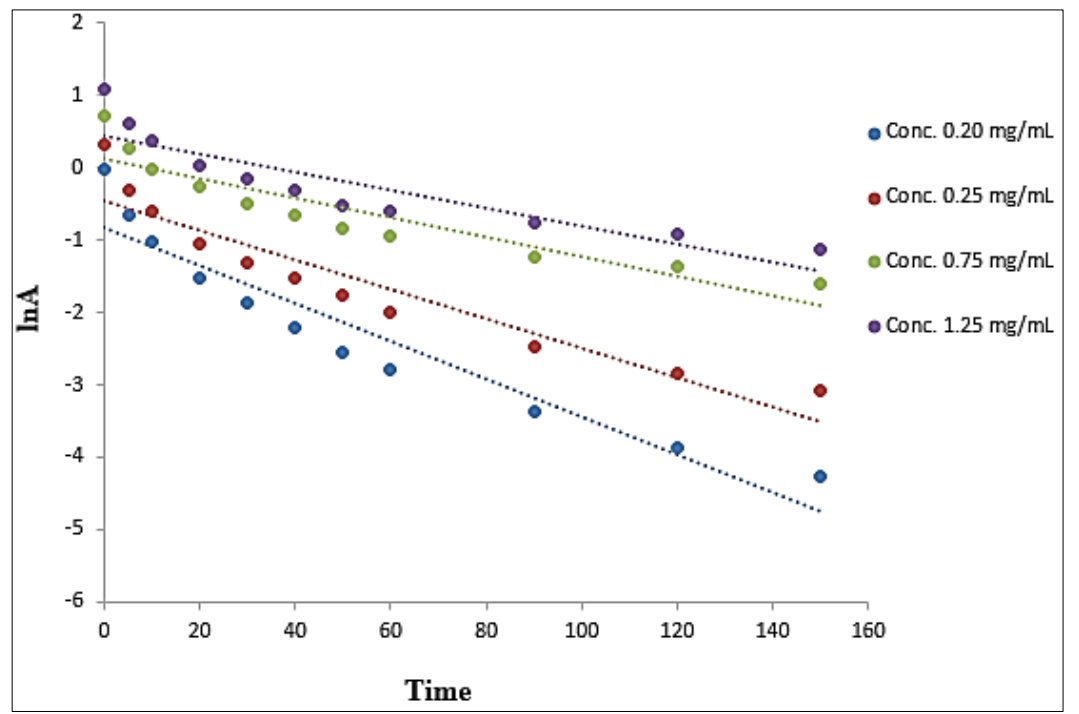

Fig 6: Changes in $\ln \mathrm{A}$ with time (min) for photodegradation of sunfix yellow dye at different initial dye concentration.

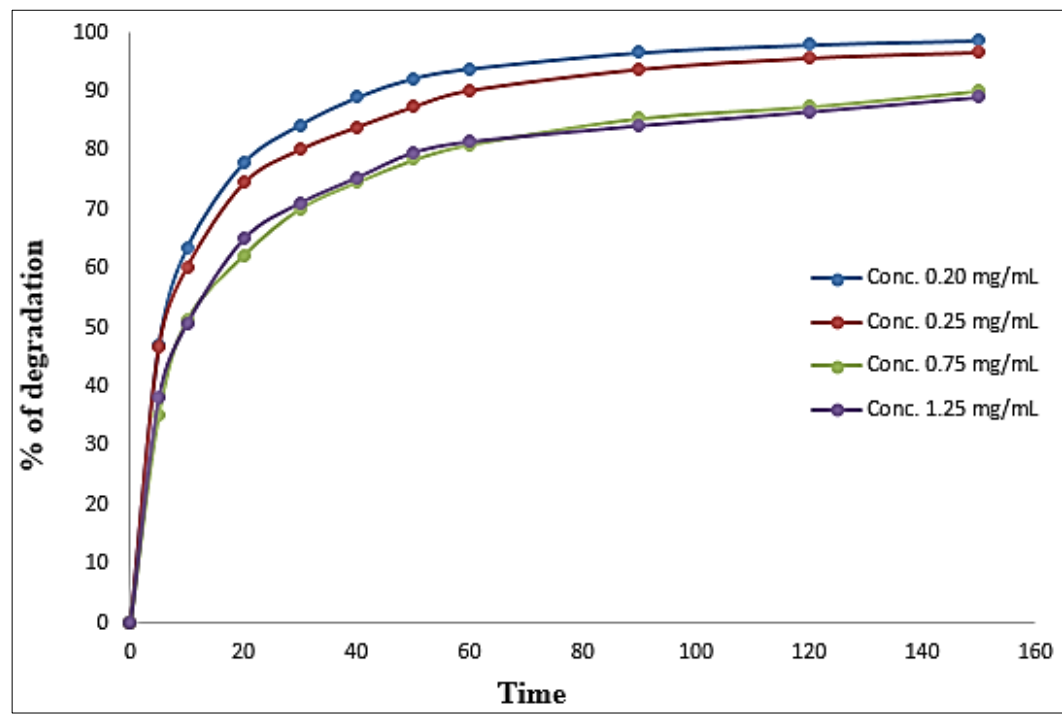

Fig 7: Changes in percent $(\%)$ of degradation with time (min) for photodegradation of sunfix yellow dye at different initial dye concentration. 
From (Table 2), demonstrated the percent (\%) of the photodegradation with a decrement manner while adding up more dye in concentration. Finally, it started to go downward with further increasing of initial dye concentration. The maximum degradation of the dye was found to be at initial dye concentration of $0.20 \mathrm{mg} / \mathrm{mL}$.

Table 2: Percent of photodegradation for the different concentration of sunfix yellow dye at the pH 10 .

\begin{tabular}{|c|c|}
\hline Dye Concentration (mg/mL) & Percent (\%) of Degradation \\
\hline 0.20 & 98.58 \\
\hline 0.25 & 96.64 \\
\hline 0.75 & 90.09 \\
\hline 1.25 & 89.05 \\
\hline
\end{tabular}

Effect of amount of $\mathrm{ZnO}$ on photodegradation of sunfix yellow dye by $\mathrm{ZnO}$

Photocatalytic degradation reactions always accompany by the action of photocatalyst and therefore it has been investigated that, any photodegradation is directly related to the amount of photocatalyst. In this study, the photodegradation is directly related to the amount of $\mathrm{ZnO}$ suspension. The effect of amount of $\mathrm{ZnO}$ on the photodegradation of sunfix yellow dye was investigated by varying the amount of $\mathrm{ZnO}$ from 0.1 to $0.8 \mathrm{~g}$ at constant dye concentration $0.25 \mathrm{mg} / \mathrm{mL}$ and certain $\mathrm{pH}$ (10) of the suspension.

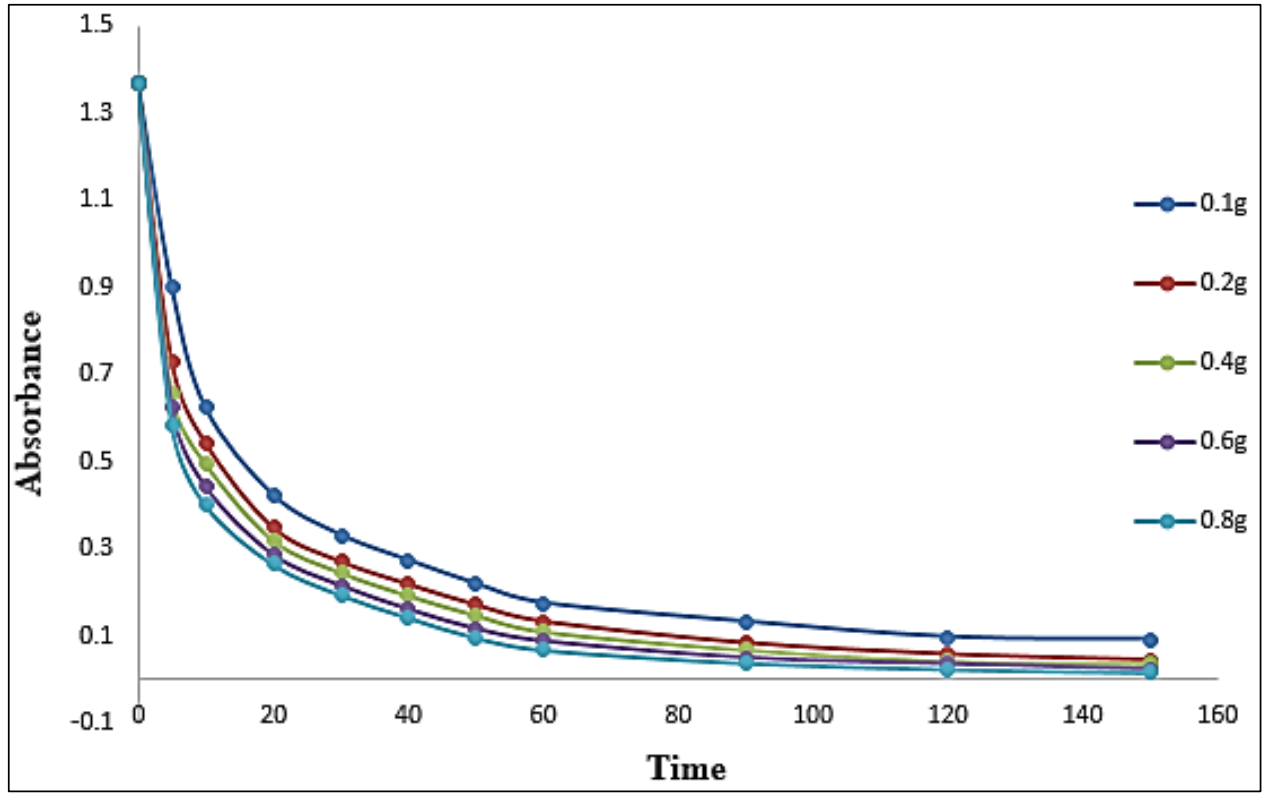

Fig 8: Changes in absorbance with time (min) for photodegradation of sunfix yellow dye at different amount of $\mathrm{ZnO}$.

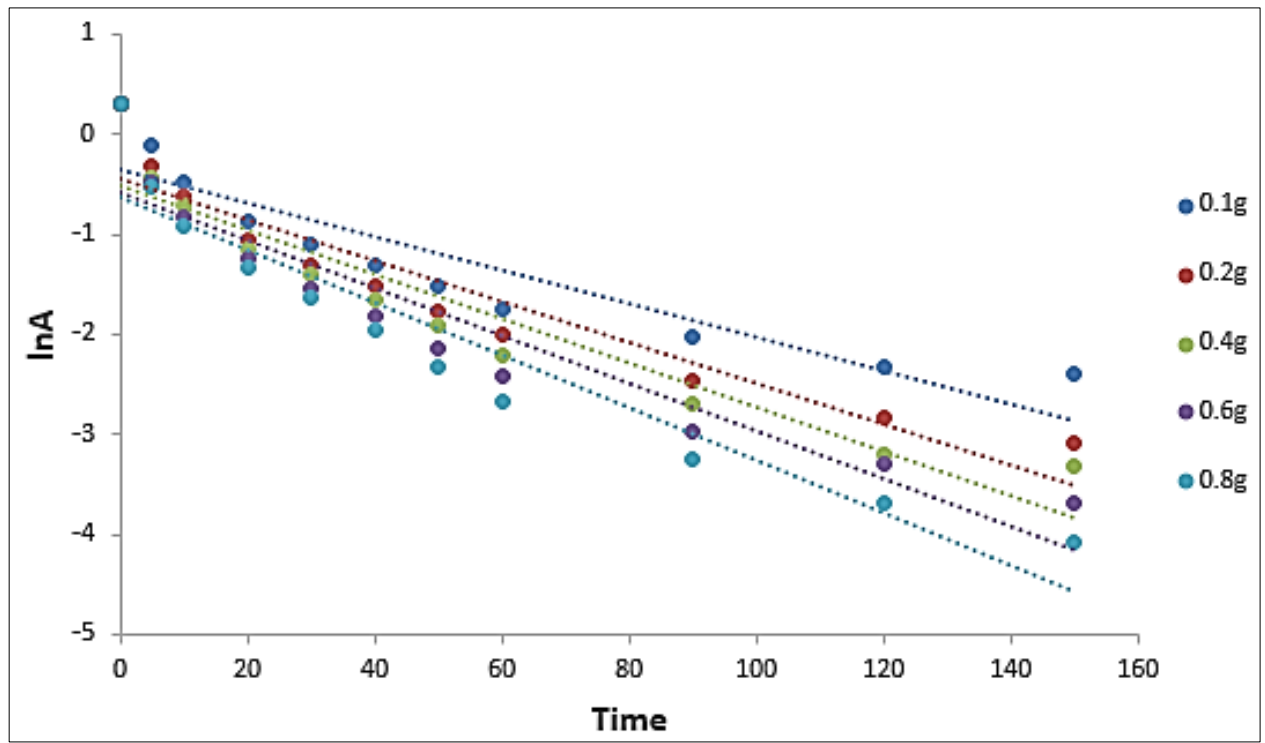

Fig 9: Changes in $\ln \mathrm{A}$ with time ( $\mathrm{min}$ ) for photodegradation of sunfix yellow dye at different amount of $\mathrm{ZnO}$. 


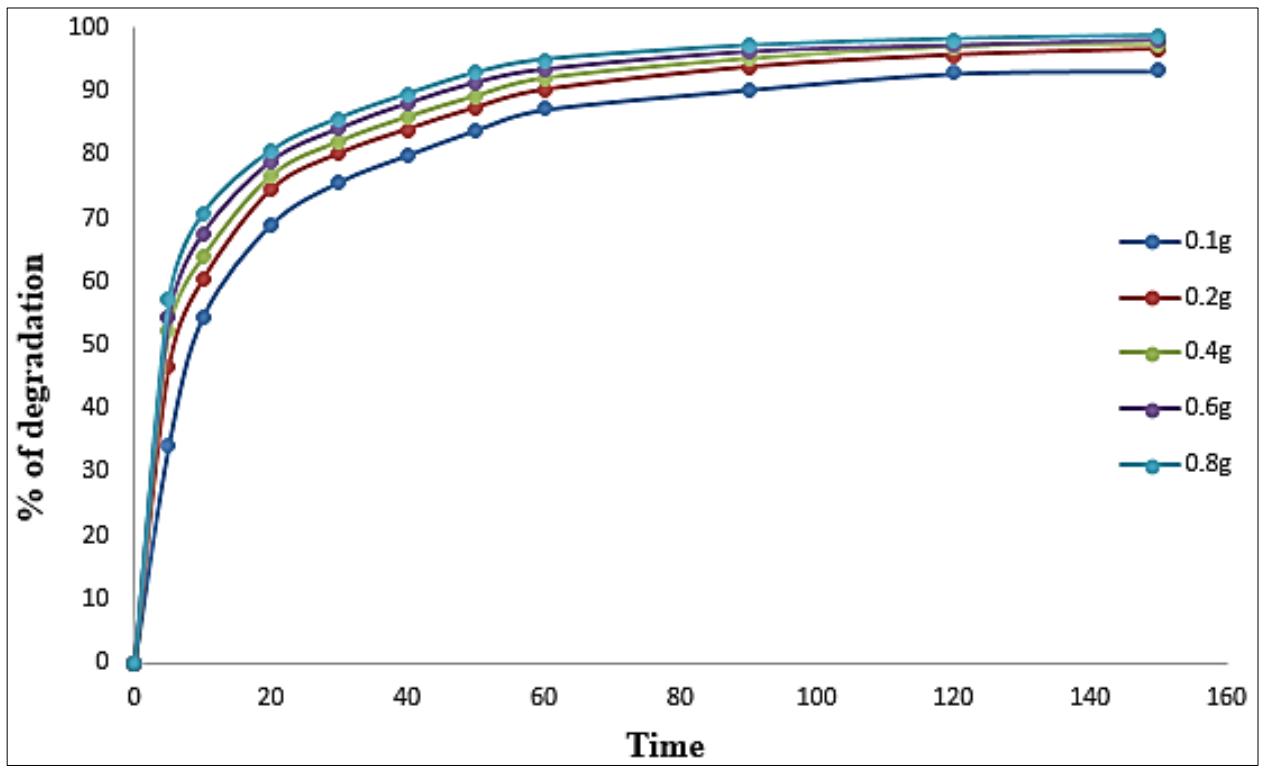

Fig 10: Changes in percent (\%) of degradation with time (min) for photodegradation of sunfix yellow dye at different amount of $\mathrm{ZnO}$.

The results showed (Table 3) that the percent (\%) of photodegradation is increased with the increase of amount of $\mathrm{ZnO}$ as expected. The optimum amount of $\mathrm{ZnO}$ was found to be $0.8 \mathrm{~g}$ for the maximum photodegradation of sunfix yellow dye.

Table 3: Percent of photodegradation of sunfix yellow dye for the different amount of $\mathrm{ZnO}$ at the $\mathrm{pH} 10$.

\begin{tabular}{|c|c|}
\hline Amount of $\mathbf{Z n O}(\mathbf{g})$ & Percent (\%) of Degradation \\
\hline 0.1 & 93.28 \\
\hline 0.2 & 96.64 \\
\hline 0.4 & 97.37 \\
\hline 0.6 & 98.17 \\
\hline 0.8 & 98.75 \\
\hline
\end{tabular}

\section{Kinetics of degradation}

Kinetic investigation is very vital for a certain reaction because kinetic investigation usually exhibits the dependency of the rate of the reaction on the concentration of reactants and other influencing parameter that should be carefully managed for the attainment of better result. The kinetic parameters like values of pseudo first order rate constant $\left(\mathrm{k}_{1}\right)$, initial rate constant $\left(\mathrm{R}_{\mathrm{i}}\right)$ and $\mathrm{R}^{2}$ for photodegradation of sunfix yellow dye were determined in this study those are enrolled in (Table 4). The kinetic investigation of the photodegradation of sunfix yellow dye reveals that the kinetic follow the pseudo first order kinetics.

Table 4: The Pseudo first order kinetics parameter for the photodegradation of sunfix yellow dye.

\begin{tabular}{|c|c|c|c|}
\hline \multirow{2}{*}{ Parameter } & \multicolumn{3}{|c|}{ Pseudo first order kinetics model } \\
\hline & $\mathbf{k}_{1}\left(\min ^{-1}\right)$ & Initial rate, $R_{\mathrm{i}} \times 10^{-8}\left(\mathrm{M}^{-1} \mathrm{~min}^{-1}\right)$ & $\mathbf{R}^{2}$ \\
\hline pH & \multicolumn{3}{|c|}{ Here, initial dye concentration $(0.25 \mathrm{mg} / \mathrm{mL})$ and amount of $\mathrm{ZnO}(0.2 \mathrm{~g})$ are constant } \\
\hline 2 & 0.009 & 0.0022 & 0.959 \\
\hline 3 & 0.011 & 0.0027 & 0.961 \\
\hline 4 & 0.014 & 0.0035 & 0.958 \\
\hline 5 & 0.016 & 0.0040 & 0.956 \\
\hline 6 & 0.019 & 0.0047 & 0.942 \\
\hline 7 & 0.021 & 0.0052 & 0.926 \\
\hline 8 & 0.023 & 0.0057 & 0.897 \\
\hline 9 & 0.024 & 0.0060 & 0.861 \\
\hline 10 & 0.027 & 0.0067 & 0.892 \\
\hline 11 & 0.025 & 0.0062 & 0.862 \\
\hline Initial dye concentration $(\mathrm{mg} / \mathrm{mL})$ & \multicolumn{3}{|c|}{ Here, $\mathrm{pH}(10)$ and amount of $\mathrm{ZnO}(0.2 \mathrm{~g})$ are constant } \\
\hline 0.20 & 0.023 & 0.0046 & 0.911 \\
\hline 0.25 & 0.027 & 0.0050 & 0.891 \\
\hline 0.75 & 0.013 & 0.0097 & 0.846 \\
\hline 1.25 & 0.012 & 0.0150 & 0.801 \\
\hline $\mathrm{ZnO}(\mathrm{g})$ & \multicolumn{3}{|c|}{ Here, pH (10) and initial dye concentration $(0.25 \mathrm{mg} / \mathrm{mL})$ are constant } \\
\hline 0.1 & 0.016 & 0.0040 & 0.843 \\
\hline 0.2 & 0.027 & 0.0050 & 0.891 \\
\hline 0.4 & 0.029 & 0.0055 & 0.894 \\
\hline 0.6 & 0.031 & 0.0057 & 0.892 \\
\hline 0.8 & 0.033 & 0.0065 & 0.904 \\
\hline
\end{tabular}

\section{Conclusions}

The photodegradation of sunfix yellow dye was studied in aqueous solutions using $\mathrm{ZnO}$ suspension as photocatalyst. The effect of $\mathrm{pH}$ on photodegradation of sunfix yellow dye in presence of $\mathrm{ZnO}$ photocatalyst was also investigated as photocatalytic degradations are always $\mathrm{pH}$ dependent as well 
as like photoreactions always take place on the surface of photocatalyst. The optimum $\mathrm{pH}$ for the photodegradation of sunfix yellow dye in presence of $\mathrm{ZnO}$ photocatalyst was attained to be 10 as there was an enhanced trend of rising photodegradation. The optimum time was obtained to be 150 minutes as there was no degradation after this period of time assuming approximately whole dye concentration reduced due to degradation. The optimum amount of the photocatalyst was achieved to be $0.2 \mathrm{~g} \mathrm{ZnO}$ suspension as the degradation was highest with this amount containing the optimum dye concentration $0.25 \mathrm{mg} / \mathrm{mL}$ of sunfix yellow dye having a photodegradation percentage of $96.64 \%$. This result, thus explore that the photocatalytic degradation of sunfix yellow dye is favorable in alkaline media as well as it is a time dependent process, which can be regarded as an important aspects in removing dyes from wastewater discharged from a wide variety of industries.

\section{Acknowledgement}

The authors are thankful to Department of Chemistry, Jahangirnagar University, Dhaka 1342 and Department of Chemistry, Mawlana Bhashani Science and Technology University, Tangail 1902 for providing all necessary facilities.

\section{References}

1. Zuo R, Du G, Zhang W, Liu L, Liu Y, Mei L et al. Photocatalytic Degradation of Methylene Blue Using $\mathrm{TiO}_{2}$ Impregnated Diatomite. Adv. Mater. Sci. Eng, 2014, 1-7.

2. Lam SM, Sin JC, Abdullah AZ, Mohamed AR. Degradation of wastewaters containing organic dyes photocatalysed by zinc oxide: a review. Desalination Water Treat. 2012; 41(1-3):131-169.

3. Robinson $\mathrm{T}$ et al. Remediation of dyes in textile effluent: A critical review on current treatment technologies with a proposed alternative. Bioresour. Technol. 2001; 77(3):247-275.

4. Khataee AR, Zarei M, Moradkhannejhad L. Application of response surface methodology for optimization of azo dye removal by oxalate catalyzed photoelectro-Fenton process using carbon nanotube-PTFE cathode. Desalination. 2010; 258:112-119.

5. Islam A, Ferdous T, Das AK, Karim MM, Masum SM. Photocatalytic degradation of Direct Brown RN dye in the presence of $\mathrm{ZnO}$ nanoparticles. Bangladesh J. Sci. Ind. Res. 2015; 50(1):1-6.

6. Crini G. Non-conventional low-cost adsorbents for dye removal: A review. Bioresour. Technol. 2006; 97(9):1062-1070.

7. Malik R, Ramteke DS, Wate SR. Adsorption of malachite green on groundnut shell waste based powdered activated carbon. Waste management. 2006; 27(9):1-8.

8. Chatterjee D, Dasgupta S. Visible light induced photocatalytic degradation of organic pollutants. J. Photochem. Photobio. C: Rev. 2005; 6:186-205.

9. Cataño FA, Valencia SH, Hincapié EA, Restrepo GM, Marín JM. A Comparative Study between $\mathrm{TiO}_{2}$ and $\mathrm{ZnO}$ Photocatalysis: Photocatalytic Degradation of Cibacron Yellow FN-2R Dye. Lat. Am. Appl. Res. 2012; 42:33-38.

10. Uphade BK, Thorat DG, Gadhave AG, Kadnor VA. Degradation of Dye Using CUS-CDS as a Photocatalyst. Asian Journal of Research in Chemistry. 2011; 4(12):1892-1894.

11. Nasw C, Vinpdgopal K, Hotchandaf S, Chattopadhya AK, Kamat PV. Photocatalytic reduction of azo dyes naphthol blue black and disperse blue 79 . Res. Chem. Intermed. 1997; 23(3) 219-231.

12. $\mathrm{Xu} \mathrm{Y}$, Langford $\mathrm{CH}$. UV- or Visible-Light-Induced Degradation of X3B on $\mathrm{TiO}_{2}$ Nanoparticles: The Influence of Adsorption. Langmuir. 2001; 17:897-902.

13. Stylidi M, Kondarides DI, Verykios XE. Pathways of solar light induced photocatalytic degradation of azo dyes in aqueous $\mathrm{TiO}_{2}$ suspensions. Applied Catalysis B: Environmental. 2003; 40:271-286.

14. Sangchakr B, Hisanaga T, Tanaka K. Photocatalytic degradation of sulfonated aromatics in $\mathrm{ZnO}$ suspension. J. Photochem Photobiol. A: Chem. 1995; 85:187-190.

15. Tanaka K, Padermpole K, Hisanaga T. Photocatalytic Degradation of Commercial Azo Dyes. Wat. Res. 2000; 34(1): 327-333.

16. Neppolian B, Choi CH, Sakthivel S, Arabindoo B, Murugesan V. Solar light induced and $\mathrm{ZnO}$ assisted degradation oftextile dye reactive blue 4 . Chemosphere. 2002; 46: 1173-1181.

17. Silva, da CG, Faria JL. Photochemical and photocatalytic degradation of an azo dye in aqueous solution by UV irradiation. J. Photochem. Photobiol. A: Chem. 2003; 155: 133-143.

18. Guillard C, Lachheb H, Houas A, Ksibi M, Elaloui E, Herrmann JM. Influence of chemical structure of dyes, of $\mathrm{pH}$ and of inorganic salts on their photocatalytic degradation by $\mathrm{TiO}_{2}$ comparison of the efficiency of powder and supported $\mathrm{TiO}_{2}$. J. Photochem. Photobiol. A: Chem. 2003; 158: 27-36.

19. Reza KM, Kurny ASW, Gulshan F. Parameters affecting the photocatalytic degradation of dyes using $\mathrm{TiO}_{2}$ : a review. Appl. Water Sci. 2017; 7: 1569-1578.

20. Arslan I. et al. $\mathrm{H}_{2} \mathrm{O}_{2} / \mathrm{UV}-\mathrm{C}$ and $\mathrm{Fe}^{2+/} \mathrm{H}_{2} \mathrm{O}_{2} / \mathrm{UV}-\mathrm{C}$ versus $\mathrm{TiO}_{2} / \mathrm{UV}-\mathrm{A}$ treatment for reactive dye wastewater. J. Environ. Eng. 2000; 126(10): 903.

21. Stock $\mathrm{N}$ et al. Combinative sonolysis and and photocatalysis for textile dye degradation. Environ. Sci. Tech. 2000; 34(9): 1747. 